\title{
Overcoming the dichotomy of implementing societal flood risk management while conserving instream fish habitat - a long-term study from a highly modified urban river
}

Angelopoulos N. V. ${ }^{*}$, Harvey J. P. ${ }^{1}$, Bolland J. D. ${ }^{1}$, Nunn A. D. ${ }^{1}$, Noble R. A. A. ${ }^{1}$, Smith M. A. ${ }^{1}$, Taylor M. J. ${ }^{1}$, Masters J. E. G². \& Moxon J. ${ }^{2} \&$ Cowx I. G. ${ }^{1}$

${ }^{1}$ Hull International Fisheries Institute, School of Environmental Sciences, University of Hull, Hull HU6 $7 R X, U K$

${ }^{2}$ Environment Agency. Fisheries, Biodiversity and Geomorphology. Yorkshire Area. Lateral, 8 City Walk. Leeds LS11 9AT

${ }^{*}$ Correspondence

email: n.angelopoulos@hull.ac.uk

(C) 2018. This manuscript version is made available under the CC-BY-NC-ND 4.0 license http://creativecommons.org/licenses/by-nc-nd/4.0/ 


\section{Abstract}

Flood Risk Management (FRM) is often essential to reduce the risk of flooding to properties and infrastructure in urban landscapes, but typically degrades the habitats required by many aquatic animals for foraging, refuge and reproduction. This conflict between flood risk management and biodiversity is driven by conflicting directives, such as the EU Floods and Water Framework Directives, and has led to a requirement for synergistic solutions for FRM that integrate river restoration actions. Unfortunately, ecological monitoring and appraisal of combined FRM and river restoration works is inadequate. This paper uses a case study from the River Don in Northern England to evaluate the effects of the FRM and subsequent river restoration works on instream habitat and the associated fish assemblage over an 8-year period.

Flood risk management created a homogeneous channel but did not negatively affect fish species composition or densities, specifically brown trout. Densities of adult brown trout were comparable pre and post-FRM, while densities of juvenile bullhead and brown trout increased dramatically post FRM. River restoration works created a heterogeneous channel but did not significantly improve species composition or brown trout density. Species composition post-river restoration works returned to that similar to pre-FRM over a short-term period, but with improved numbers of juvenile bullhead. Although habitat complexity increased after river restoration works, long-term changes in species composition and densities were marginal, probably because the river reset habitat complexity within the time framework of the study.

\section{Keywords:}

Urban river, climate change, river rehabilitation, policy, fisheries, European directives. 


\section{Introduction}

Floods are an integral component of natural hydrological regimes (Junk et al. 1989; Tockner et al. 2000; Acreman et al. 2014), but can cause substantial damage to property and infrastructure, and more frequent extreme precipitation events, as predicted by the IPCC (2014), will increase the risk of flooding. Furthermore, the risk and severity of flooding will particularly increase in many parts of industrialised countries, where urban areas are more prevalent and flooding is exacerbated by the cumulative impacts of multiple anthropogenic pressures, such as channel engineering, artificial structures and impervious riparian surfaces, which increase run-off volume and river discharge (Butler \& Pidgeon 2011). Flooding in urban areas has had devastating effects on people, property, infrastructure and the economy worldwide in recent decades (Everard \& Moggridge 2012), and is likely to increase in frequency and magnitude in the future (IPCC 2014).

Flood Risk Management (FRM) interventions reduce the risk of flooding to properties and infrastructure in urban and rural landscapes. FRM typically involves modification of river channels to enhance the conveyance of flood water, for example through with the removal of meanders, river substrate, riparian vegetation and instream features, such as islands (Roni \& Beechie 2013). Conventional FRM also involves construction of extensive flood defence structures, such as in Rotterdam in the Netherlands, New Orleans in the United States and the Huai River in China, where main river channels have been isolated from their floodplains (Sayers et al. 2013). This isolation profoundly affects fluvial processes and ecosystem functioning, and also eliminates or degrades the habitats required by many aquatic animals for foraging, refuge and reproduction (Bernhardt \& Palmer 2007; Weber \& Wolter 2016; Zajicek et al. 2018).

There is inevitably a need to compromise between FRM and biodiversity, especially if both are enshrined in legislation, such as the EU Floods Directive (FD (2007/60/EC)), Water Framework Directive (WFD (2000/60/EC))) and Habitats Directive (HD (92/43/EEC)) (Jackson et al. 2016). This has led to a requirement for synergistic solutions for FRM that integrate river restoration works (RRW) into their planning and implementation, to optimise benefits for both agendas (Rouillard et al. 2015; Friberg et al. 2016; Jackson et al. 2016). Although this integrated FRM and RRW approach is widely supported in principle, it is still in its infancy with only a few studies evaluating the ecological impact of FRM (Collas et al. 2018), meaning evidence of its application, efficacy and/or success in practice is limited. The majority of existing literature evaluates flood management measures and impacts on society, but ecological monitoring and appraisal of FRM and RRW to determine the effectiveness of such projects is typically weak, due in part to limited timescales and resourcing of such studies (Adams et al., 2014; Angelopoulos et al. 2017). As flood risk increases globally due to climate change, and societal and environmental policy changes are expected in the near future (Wiering et al. 2017), there is a need to advance knowledge about FRM impacts on urban river ecosystems. To do this, ecological assessment needs to be integrated into FRM planning to evaluate how it changes habitat and aquatic biota, but this is rarely done, presenting a critical knowledge gap that is the key focus of this paper (Roni \& Beechie 2013). 
In June 2007, 4000 homes and 1800 businesses were flooded during a 1-in-150-year event in the City of Sheffield, United Kingdom (Pitt Review 2008), which resulted in FRM actions in 2009 to reduce the risk of further flooding, and then RRW in 2010 and 2011 to rehabilitate instream fish habitat. Fish are key ecological indicators of the ecological quality of rivers, and the impacts of FRM and RRW, because the various fish guilds integrate a wide range of habitat conditions over their life cycles that are linked to the environmental requirements of particular species and ontogenetic life stages (Weber \& Wolter 2016). This paper assesses the long term changes in physical characteristics and mean daily flow $\left(\mathrm{m}^{3} \mathrm{~s}^{-}\right.$ ${ }^{1}$ ), subsequent available habitat and the fish community in response to FRM and subsequent RRW, and is one of the first to use ecological assessment to inform future flood risk governance on the integration of river restoration.

\section{Methods}

\subsection{Site description}

The study site is located in the City of Sheffield, United Kingdom, at the confluence of the rivers Rivelin and Loxley (Ordnance Survey National Grid reference: 53.399698 -1.511562), which are regulated by Rivelin Dams (53.377511 -1.589666) and Damflask (53.413377 -1.582340) reservoirs, respectively. The site is in a highly urbanised location surrounded by impervious surfaces; there are road bridges at the upstream and downstream limits, and the river is constrained by embankments. Prior to FRM (2009) the channel was defined by riparian deciduous trees and shrubs which overhung the water surface by approximately $80 \%$, stabilised the bank and seemingly prevented meandering given their size and age, and (Figure 1a). Following a 1-in-150-year event in 2007, FRM works in October 2009 involved removing all riparian vegetation, some gravel shoals and larger instream substrates to help reduce the risk of blockages at the downstream road bridge (Figure 1). This also prevented recolonization of vegetation that would in time pose a flood risk, and optimise hydraulics around the structures to reduce the likelihood of future flooding in the surrounding urbanised area (Figure 1). Overall this created a uniform over-widened and shallow channel, and reduced variability in substratum, water depth and overall flow characteristics (Figure 1b). The channel was then re-profiled in November 2010 (after 2010 habitat and fish surveys but prior to those in 2011) as part of RRW by introducing large boulders backfilled with cobbles and gravel, as well as in-channel boulder clusters and by creating a variable longitudinal depth profile along the thalweg. These works were intended to diversify water depths and velocities to provide cover for fish (Figure 1c). In-channel substrate was highly dynamic, and mobilised by high flows in the first two years post-RRW, evidenced by a new mid-channel gravel bar forming in 2011, which had redistributed by 2012 and reformed on the right bank by 2013 (Figure 1c to e). Riparian habitats were allowed to regenerate (from 2012) through a combination of reseeding, replanting and natural recovery (Figure 1f).

Mean daily flow was $<1 \mathrm{~m}^{3} \mathrm{~s}^{-1}$ for the majority of the year, with high seasonal peaks in December to February for 2009-2010 (highest daily flow of $6.4 \mathrm{~m}^{3} \mathrm{~s}^{-1}$ ), 2012-2013 (highest daily flow of $11.6 \mathrm{~m}^{3} \mathrm{~s}^{-1}$ ), $2014\left(8 \mathrm{~m}^{3} \mathrm{~s}^{-1}\right) 2016\left(9.8 \mathrm{~m}^{3} \mathrm{~s}^{-1}\right)$ (Appendix 1). In 2015, the high flows came in March and April (highest 
daily flow of $3.8 \mathrm{~m}^{3} \mathrm{~s}^{-1}$ ) while in 2012, high flow events occurred late in the year in April (highest daily flow of $14.7 \mathrm{~m}^{3} \mathrm{~s}^{-1}$ ), June (highest daily flow of $5 \mathrm{~m}^{3} \mathrm{~s}^{-1}$ ), and July (highest daily flow of $15 \mathrm{~m}^{3} \mathrm{~s}^{-1}$ ) (Appendix 1).

\subsection{Sampling methods}

Instream habitat and fish surveys were undertaken annually between July to August in each year from 2009 to 2016 at average summer flows, with 2009 surveys representing pre-FRM, 2010 surveys postFRM and pre-RRW, and 2011-2016 surveys post-RRW.

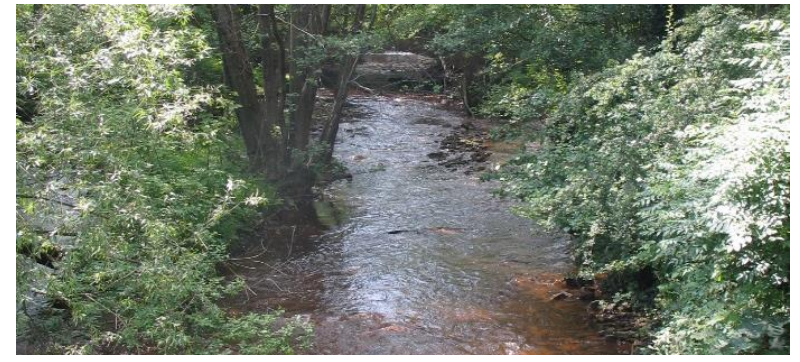

a) $03 / 07 / 2009: 0.51 \mathrm{~m}^{3} \mathrm{~s}^{-1}$

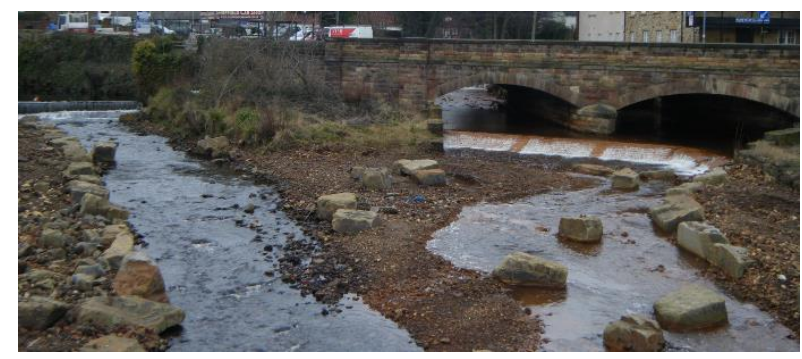

c) $19 / 07 / 2011: 0.45 \mathrm{~m}^{3} \mathrm{~s}^{-1}$

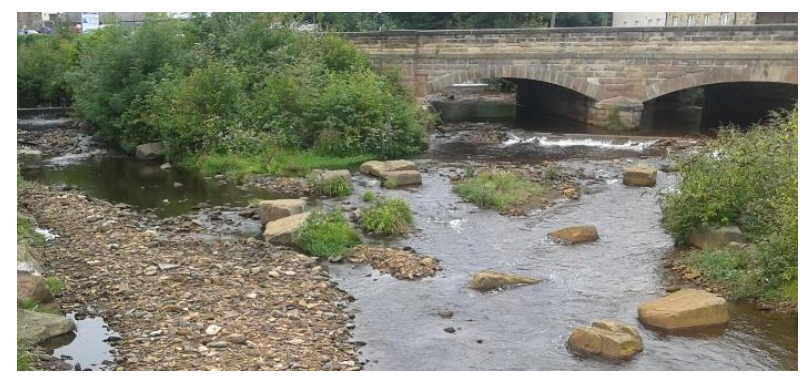

e) 20/08/2013: $0.43 \mathrm{~m}^{3} \mathrm{~s}^{-1}$

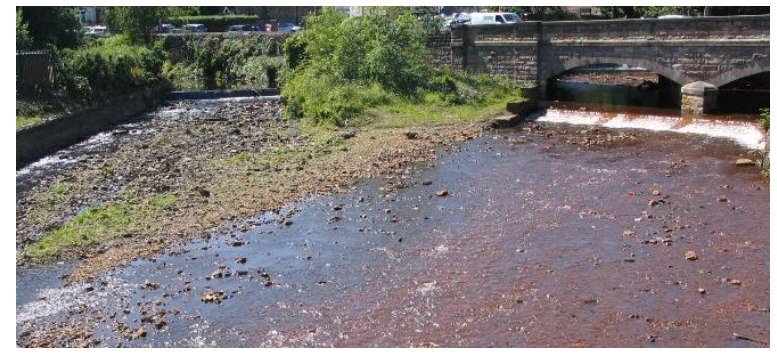

b) $21 / 07 / 2010: 0.45 \mathrm{~m}^{3} \mathrm{~s}^{-1}$

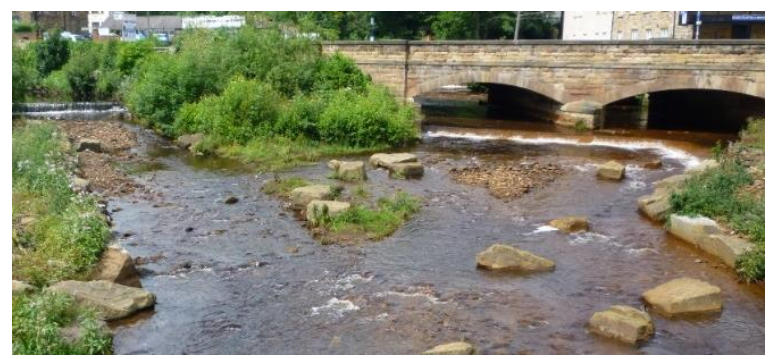

d) $19 / 07 / 2012: 0.51 \mathrm{~m}^{3} \mathrm{~s}^{-1}$

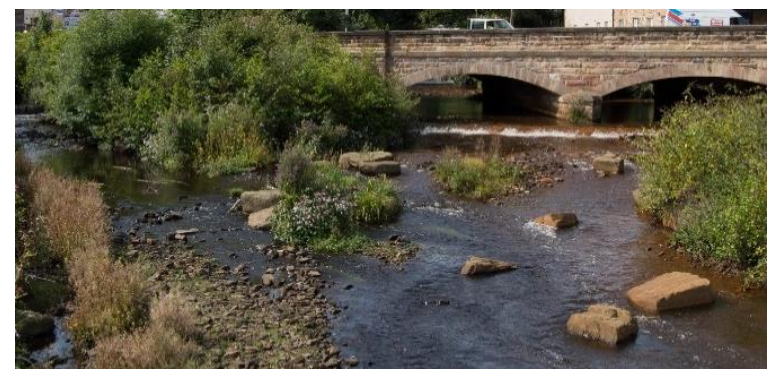

f) $14 / 08 / 2014: 0.51 \mathrm{~m}^{3} \mathrm{~s}^{-1}$ 


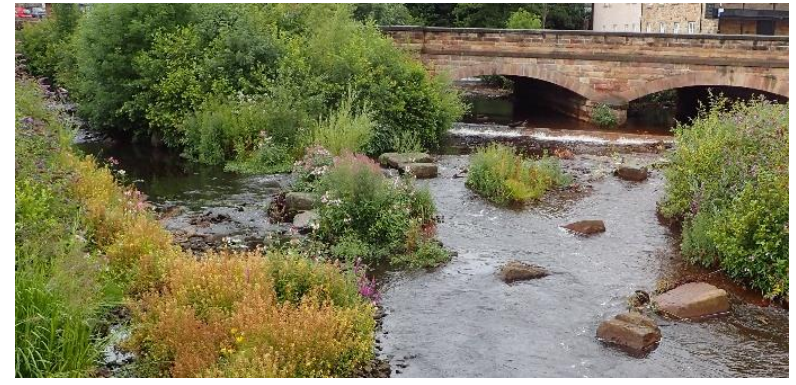

g) $22 / 09 / 2015: 0.39 \mathrm{~m}^{3} \mathrm{~s}^{-1}$

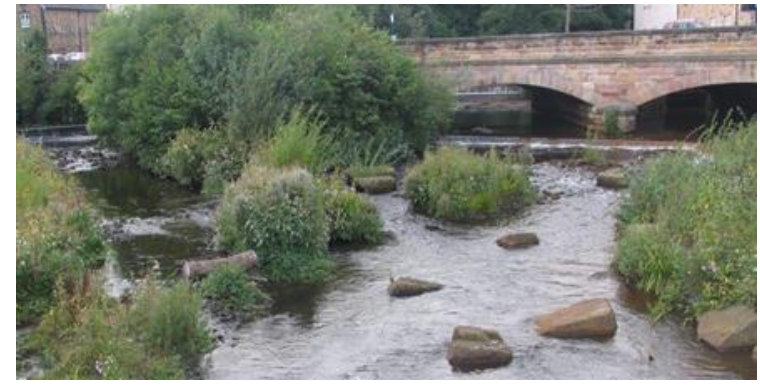

h) 12/09/2016: $0.44 \mathrm{~m}^{3} \mathrm{~s}^{-1}$

Figure 1. Fixed-point photographs of Malin Bridge on the River Loxley, northern England, (a) pre-flood risk management (FRM; 2009), (b) post-FRM (2010) and (c-h) post-river restoration (2011-2016). Photographs were taken day of sampling (53.399399-1.511251), including mean daily flow $\left(\mathrm{m}^{3} \mathrm{~s}^{-1}\right.$; Loxley Rowel Bridge Gauge 53.401963 -1.551268). IN COLOUR in online version

\subsubsection{Habitat surveys}

Instream habitat surveys were conducted using the HABSCORE methodology, an empirical habitat-fish model developed for measuring and evaluating stream salmonid habitat features that is widely used in the UK for impact assessment (Barnard \& Wyatt 1995; Wyatt et al. 1995; Milner et al. 1998). The same two experienced researchers carried out the HABSCORE field recording each year. HABSCORE is based on a series of empirical models relating the population size of five salmonid species/age combinations (juvenile 0+ Atlantic salmon Salmo salar L.; adult $\geq 1+$ salmon; juvenile $0+$ brown trout Salmo trutta L.; sub-adult $\geq 1+$ brown trout $(<20 \mathrm{~cm})$; and $\geq 1+$ brown trout $(>20 \mathrm{~cm})$ to observed habitat variables (Milner et al. 1998); salmon was excluded from the study as the species is currently absent from the upper reaches of the River Don catchment due to a number of impassable barriers downstream.

Instream habitat characteristics were measured for each 10-m section of the fish survey study site following the HABSCORE methodology. Water depth (to the nearest $0.01 \mathrm{~m}$ ) and wetted river width (to the nearest $0.1 \mathrm{~m}$ ) at $1 / 4,1 / 2$ and $3 / 4$ of the channel width were measured at the upstream and downstream limit of each $10-\mathrm{m}$ section. Substratum [bedrock, boulders ( $>25.6 \mathrm{~cm}$ longest axis length), cobbles (6.4$25.6 \mathrm{~cm}$ ), gravel $(0.2-6.4 \mathrm{~cm})$, fine sand $(<0.2 \mathrm{~cm})$ ] and flow [cascade, turbulent (deep or shallow), glide (deep or shallow) and slack (deep or shallow), where the threshold between deep and shallow water was defined as being deeper than $50 \mathrm{~cm}$ for sections with a width less than $5 \mathrm{~m}$, but as deeper than $10 \%$ of the width for sections with a width greater than $5 \mathrm{~m}$ ] categories were recorded as absent $(0 \%)$, scarce $(>0-4 \%)$, common $(5-19 \%)$, frequent $(20-49 \%)$ or dominant $(>50 \%)$ according to their contribution by surface area.

\subsubsection{Fish surveys}

Quantitative, three-catch depletion electric fishing surveys were carried out, involving three personnel (one anode operator and two netters) fishing in an upstream direction, with a fourth on the bank ensuring 
safe operation of the equipment. A 2-kVA generator powering an electric fishing control box producing a 220-V, $50 \mathrm{~Hz}$ Pulsed Direct Current output was employed. Stop nets were deployed at the upstream and downstream limits of the site, to prevent fish leaving or entering the site during the surveys. As many fish as possible were caught by netsmen either side and downstream, of the anode operator; during each of the three fishing run. Fish caught in each run were kept in separate, aerated tanks for data collection. All fish were identified to species level and measured (fork length, $\mathrm{mm}$ ), and a scale sample was taken from each fish for age and growth analysis, before being returned to the river (Bagenal \& Tesch 1978). The age of brown trout was determined by the interpretation and counting of annual growth checks (annuli) that appear on the scales of the fish (Bagenal \& Tesch 1978). Scales from each individual fish were examined under a microfiche projector and the fish aged by counting the number of annuli, taking care to note any false checks.

\subsection{Data analysis}

\subsubsection{Habitat analyses}

Mann-Whitney U-tests (data were not normally distributed) were used to explore differences in river depth and wetted width, pre (2009) to post-FRM (2010), post-FRM (2010) to post-RRW (2011) and preFRM (2009) to post RRW (2011). Kruskal-Wallis tests (data were not normally distributed and more than 2 groups) were used to explore similarity in river depth, and wetted width, between years postRRW (2011-2016).

The median value for each abundance category recorded for substratum and flow (Section 2.2.1) was used as the input value for each category (e.g. absent ( $0 \%)$, scarce ( $2.5 \%)$, common (12.5\%), frequent (35\%) or dominant (75\%).

\subsubsection{Fisheries analysis}

Only three species (brown trout, bullhead (Cottus gobio L.) and stone loach (Barbatula barbatula (L.)) were found in sufficient numbers to include in the analysis. Fish species present in low numbers $(\leq 5)$, and caught in less than two sample years were removed from the analysis. Bullheads were divided in to juvenile and adult categories based on length frequency distributions. Brown trout were divided in to juvenile $(0+)$, sub-adult ( $\geq 1+<20 \mathrm{~cm}$ in fork length) and adult $(\geq 1+>20 \mathrm{~cm}$ in fork length) categories based on ageing from scales, where $0+$ fish are from the recruitment of the sampling year and $\geq 1+$ is one year or older. There was only one category for stone loach (Barbatula barbatula (L.)). Densities ( $n$ $\pm 95 \%$ confidence limits (CL) / $100 \mathrm{~m}^{2}$ ) were calculated by dividing the estimate of population size $(\mathrm{n})$ (using the three-catch Maximum Likelihood Removal Method (Carle \& Strub 1978)) by the total wetted width area, multiplied by 100 . Fisheries data for a control site (53.390852, -1.519879) upstream of Malin Bridge was collected from the Environment Agency's National Fisheries Populations Database (https://data.gov.uk/dataset/nfpd-freshwater-fish-survey-relational-datasets).

Bray-Curtis similarity matrices (Bray and Curtis 1957) were calculated using the density estimates ( $n$ $100 \mathrm{~m}^{-2}$ ) of each fish species and age/size groups, and ordinated using non-metric multidimensional scaling (MDS) to investigate similarities in species composition. The matrices were then submitted to 
permutational multivariate analysis of variance (PERMANOVA) (999 random permutations) to assess any differences in species composition pre, post-FRM and post-RRW.

Habitat measurements and brown trout population size $(n)$ for each age/size category were entered into the HABSCORE for Windows program. The software produces two outputs (see Barnard \& Wyatt 1995; Wyatt et al. 1995) for the measure of salmonid habitat quality - Habitat Quality Score (HQS) and Habitat Utilization Index (HUI) - for three brown trout age/size categories - juvenile, sub-adult and adult - in each year (Milner et al. 1998). HQS is a prediction of the expected population density ( $\left.n \pm 90 \% \mathrm{CL} / 100 \mathrm{~m}^{2}\right)$ derived purely using physical habitat data. $\mathrm{HUI}$ is a measure of habitat utilisation by brown trout and is the ratio $( \pm 90 \% \mathrm{CL}$ ) between the observed density (fish survey data) and expected population size (HQS); HUI = 1 when observed density and HQS are identical (Barnard \& Wyatt 1995). HUI $<1$ occurs when the observed densities are less than HQS, and are significantly less when the upper CL limit of the $\mathrm{HUI}$ distribution is lower than $1(<1)$. $\mathrm{HUI}>1$ occurs when the observed densities are greater than HQS and are significantly greater when the lower CL limit of the HUI is greater than $1(>1)$.

\section{Results}

\subsection{Change in habitat}

Median site depth was $26.5 \mathrm{~cm}$ pre-FRM works (2009), while maximum depth was $80 \mathrm{~cm}$. Post-FRM works (2010) the river was significantly shallower with a median site depth of $16.0 \mathrm{~cm}(U(1)=426.5, Z$ $=-3.31, p=0.001)$ ), while the maximum depth was $55 \mathrm{~cm}$. Post-RRW (2011), median site depth increased to $23.5 \mathrm{~cm}$ and was significantly deeper than post-FRM $(2010)(U(1)=469.0, Z=-2.02, p=$ 0.043), but was similar to the median site depth pre-FRM (2009) $(U(1)=647.0, Z=-1.093, p=0.27$ ). Between 2011 and 2016 median site depths were similar, ranging between $20.0 \mathrm{~cm}$ and $27.5 \mathrm{~cm}$.

The median site wetted width was $12.05 \mathrm{~m}$ pre-FRM works (2009), while the maximum wetted width was $13.4 \mathrm{~m}$. Post-FRM works (2010) the wetted width was wider than pre-FRM (2009) with a median site width of $16.6 \mathrm{~m}$, but not significantly wider $(U(1)=14.0, Z=-1.62, p=0.113$ ), while the maximum wetted width was $21.4 \mathrm{~m}$. Post-RRW (2011), the median wetted width decreased to $12.0 \mathrm{~m}$ but was not significantly narrower than $2010(U(1)=14.0, Z=-1.41, p=0.175)$ and was a similar wetted width to pre-FRM (2009) $(U(1)=26.0, Z=-0.232, p=0.842)$. The maximum wetted width post-RRW (2011) was $17.2 \mathrm{~m}$. Between 2011 and 2016 the median wetted widths ranged between $12.0 \mathrm{~m}$ (2011) and $18.6 \mathrm{~m}$ (2014), but changes in widths over the study did not differ significantly between years $\left(X^{2}(5)=8.22, p\right.$ $=0.145$ ).

Pre-FRM works (2009), cobbles were the dominant (62\%) substrate type, gravel was frequent (21\%) and all other substrate categories covered $\leq 10 \%$ of the riverbed (Figure 2a). Post-FRM works (2010) cobbles remained the dominant (63\%) substrate, whilst the surface area of gravel reduced by $10 \%$ and boulders increased by $13 \%$ (Figure 2a). Turbulent shallow water was the dominant flow type (57\%) preFRM (2009) and increased to (82\%) post-FRM works (2010) (Figure 2b). There was small variability between other flow categories pre-FRM, with each category having $<20 \%$ coverage, and this reduced to $<10 \%$ post-FRM works (Figure $2 b$ ). 
Post-RRW (2011-2016) cobbles remained the dominant (40 - 60\%) substrate type, with the exception of 2013 when gravel was dominant (46\%) (Figure 2a). Boulders were the next dominant substrate type (21 - 40\%) with the exception of 2013 and 2014 when gravel covered a higher percentage of the river bed, $46 \%$ and $28 \%$, respectively (Figure 2a). Post-RRW (2011-2016) the diversity of flow types increased when compared to 2010, but not 2009 (Figure 2b). Turbulent shallow water remained the dominant flow type (44 - 65\%) across all years (2011 to 2016$)$ followed by glide shallow (14 - 37\%), with the exception of 2013 when glide shallow (20\%) and slack shallow (22\%) were similar (Figure $2 b$ ).

a)

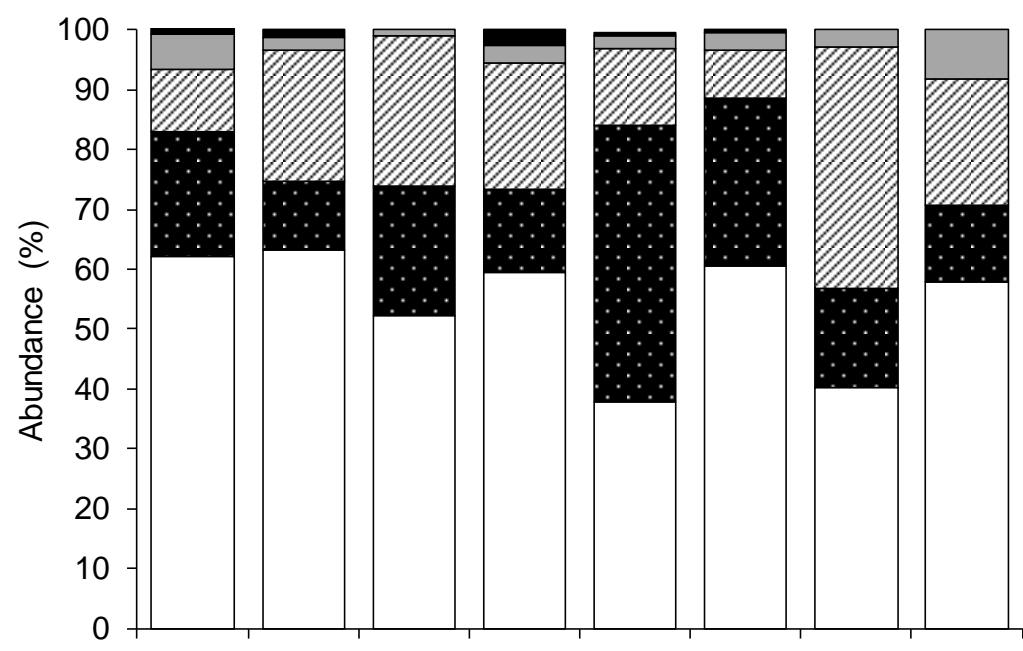

\author{
- Bedrock \\ $\square$ Fine sand \\ ฤ Boulders \\ - Gravel \\ $\square$ Cobbles
}

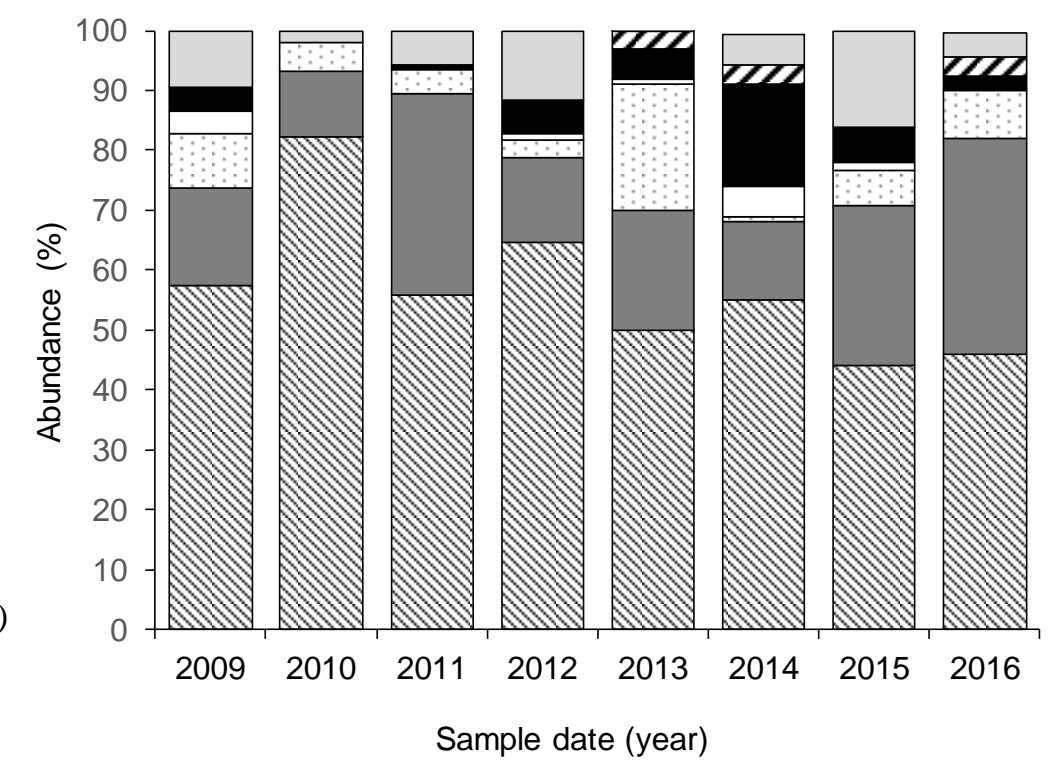

$\square$ Cascade

口 Slack deep

- Glide deep

$\square$ Turbulent deep

$\square$ Slack shallow

$\square$ Glide shallow

$₫$ Turbulent shallow

Figure 2. Abundance categories for a) substrate and b) flow, pre flood risk management (FRM; 2009), post FRM (2010) and post river restoration works (RRW; 2011-2016).

\title{
3.2 Fish species composition
}

Ten species of fish were caught during the 8 years of sampling (2009-2016), but only bullhead, brown trout and stone loach were common across all years (Appendix 2). There were dissimilarities in species 
composition across the study period (2009 to 2016) shown by changes in the continuum between each year (Figure 4). Pre-FRM (2009), adult bullhead was the dominant species $\left(n=24\right.$ per $\left.100 \mathrm{~m}^{2}\right)$ followed by sub-adult brown trout $\left(n=11\right.$ per $\left.100 \mathrm{~m}^{2}\right)$, while the density of all other species categories was $\leq 10$ per $100 \mathrm{~m}^{2}$ (Figure 5). An increase in the densities of juvenile brown trout ( $\mathrm{n}=35$ per $100 \mathrm{~m}^{2}$ ), and juvenile and adult bullhead ( $n=14$ per $100 \mathrm{~m}^{2}$ and $n=39$ per $100 \mathrm{~m}^{2}$ ) post-FRM (2010) explain the change in trajectory (Figure $4 \& 5$ ), but the shift in species composition was not significant (PERMANOVA, d.f. $=2, F=0.86, P=0.50$ ).

Resemblance: 517 Bray Curtis similarity

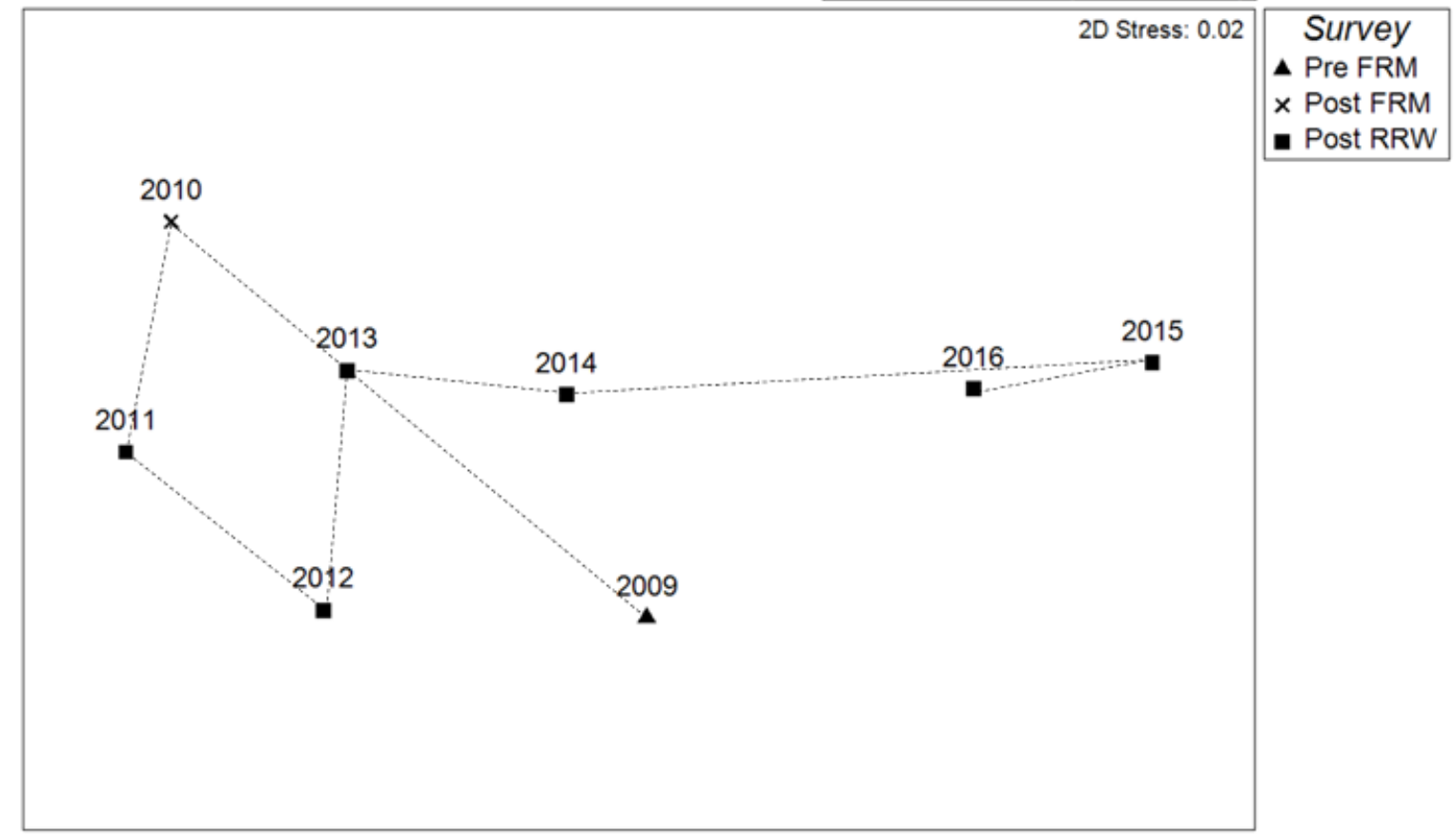

Figure 4. Non-metric multidimensional scaling (MDS) ordination plot comparing brown trout (juvenile, sub-adult and adult), bullhead (juvenile and adult) and stone loach species composition pre flood risk management (FRM; 2009), post FRM (2010) and post river restoration works (RRW; 2010-2016).

There were dissimilarities in species composition pre-FRM and post-RRW (2011) and across all postRRW year (2011 to 2016) (Figure 4). Adult bullhead was the dominant species across all years postRRW (2011-2016) with densities ranging from 58 (2011) to 9 (2014) per $100 \mathrm{~m}^{2}$, while in 2011 juvenile brown trout densities reduced to 8 per $100 \mathrm{~m}^{2}$ similar to the pre-FRM (2009), and continued to decline in 2012 to 0.4 per $100 \mathrm{~m}^{2}$, before increasing and stabilising at a similar level between 2013 (7 per 100 $\left.\mathrm{m}^{2}\right)$ and $2016\left(1\right.$ per $100 \mathrm{~m}^{2}$ ). Post-RRW (2011-2016) juvenile bullhead densities were the highest in $2011\left(17\right.$ per $\left.100 \mathrm{~m}^{2}\right)$ and reduced to $>10$ per $100 \mathrm{~m}^{2}$ for all other years post RRW, with the exception of 2012 when density was 0.1 per $100 \mathrm{~m}^{2}$ (Figure 5). Sub-adult brown trout densities increased postRRW in 2011 (20 per $\left.100 \mathrm{~m}^{2}\right)$ and 2012 (13 per $100 \mathrm{~m}^{2}$, then decreased in $2013\left(6\right.$ per $\left.100 \mathrm{~m}^{2}\right)$ and remained similar between 2014 and 2016 (Figure 5). Adult brown trout and stone loach densities remained low ( $<5$ per $100 \mathrm{~m}^{2},<1$ per $100 \mathrm{~m}^{2}$, respectively) throughout the whole of the study (Figure 
5). The variability in species composition caused a change in trajectory between 2010 (post-FRM) and 2011 (post-RRW), but this was not significant (Figure 4; PERMANOVA, d.f. $=2, F=0.86, P=0.51$ ). Species variability between years post-RRW (2011-2016) was also not significant (Figure 4; PERMANOVA, d.f. $=2, F=0.86, P=0.50$ ).

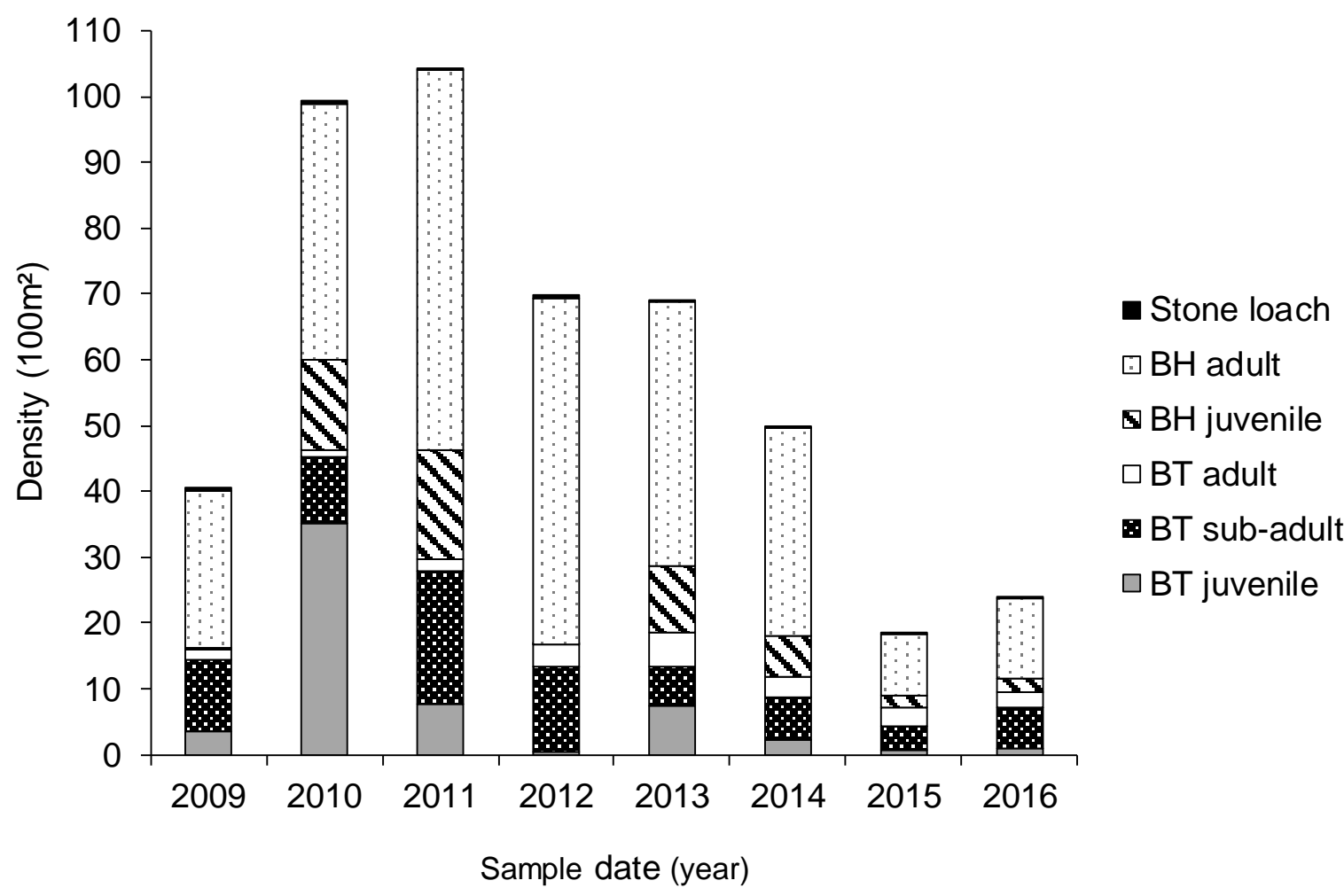

Figure 5. Density categories for species composition pre-flood risk management (FRM; 2009), post FRM (2010) and post river restoration works (RRW; 2010-2016). BH = bullhead; BT = brown trout.

\subsubsection{Brown trout}

Pre-FRM (2009), the HQS for juvenile brown trout was 4.33 per $100 \mathrm{~m}^{2}$ and comparable to the observed density of 3.62 per $100 \mathrm{~m}^{2}$ (Figure 6a). Post-FRM (2010), the HQS was 3.84 per $100 \mathrm{~m}^{2}$, the lowest in the study period, but the observed density increased to 35.14 per $100 \mathrm{~m}^{2}$, which was significantly higher than expected (HUI lower CL >1) (Figure 6a). Post-RRW (2011-2016), the HQSs for juvenile brown trout were all higher (4.47-6.83 per $100 \mathrm{~m}^{2}$ ) than pre-FRM (2009), but observed densities were highly variable, ranging from 0.38 to 7.34 per $100 \mathrm{~m}^{2}$ (in 2012 and 2013, respectively), and the observed density in 2012 was significantly lower than expected (HUI upper $\mathrm{CL}<1$ ) (Figure 6a).

Pre-FRM (2009), the HQS for sub-adult brown trout was 2.06 per $100 \mathrm{~m}^{2}$, whereas the observed density was 10.73 per $100 \mathrm{~m}^{2}$, five times the HQS but not significantly higher ( $\mathrm{HUl}$ lower $\mathrm{CL}<1$ ) (Figure 6b). Post-FRM (2010), the HQS reduced to 0.64 per $100 \mathrm{~m}^{2}$, the lowest in the study (Figure 6b), whereas 
the observed density of 10.06 per $100 \mathrm{~m}^{2}$ was slightly lower than pre-FRM but significantly higher than expected (HUI lower CL >1) (Figure 6b). Post-RRW (2011-2016); the HQSs were higher than pre-FRM; in 2011 (2.82 per $\left.100 \mathrm{~m}^{2}\right), 2015$ (3.62 per $\left.100 \mathrm{~m}^{2}\right)$ and 2016 (2.25 per $\left.100 \mathrm{~m}^{2}\right)$, and almost identical to pre-FRM in 2012 (2.03 per $\left.100 \mathrm{~m}^{2}\right)$ and $2014\left(2.04\right.$ per $\left.100 \mathrm{~m}^{2}\right)$, and lower than pre-FRM in $2013(1.60$ per $100 \mathrm{~m}^{2}$ ) (Figure 6b). Observed densities for sub-adult brown trout were higher than expected in all years, with densities in 2011 (20.10 per $100 \mathrm{~m}^{2}$ ) and 2012 (13.04 per $100 \mathrm{~m}^{2}$ ) higher than pre-FRM (Figure 6b). The higher densities in 2011 and 2012 were mostly a result of $1+$ trout, recruited in 2010. Pre-FRM (2009), the HQS for adult brown trout was 2.55 per $100 \mathrm{~m}^{2}$, double the observed density of 1.16 per $100 \mathrm{~m}^{2}$ (Figure 6c). Post-FRM (2010), the HQS reduced to 0.78 per $100 \mathrm{~m}^{2}$, the lowest in the study (Figure 6c) and observed density (1.09 per $100 \mathrm{~m}^{2}$ ) was slightly lower than pre-FRM (2009), but significantly higher than expected (HUI lower $\mathrm{CL}>1$ ) (Figure 6c).

Post-RRW (2011-2016), the HQSs were all lower (0.79-2.28 per $\left.100 \mathrm{~m}^{2}\right)$ than pre-FRM (2009) (Figure $6 \mathrm{c}$ ), whereas the observed densities (1.87-5.03 per $100 \mathrm{~m}^{2}$ ) were higher than pre-FRM (2009) and significantly higher than expected (HUI lower CL >1) in 2013 (Figure 6c).

Densities of brown trout at the control site on the River Loxley followed similar trends to the Malin Bridge impacted site during the pre-FRM period, post-FRM and post-RRW periods with the exception of the strong recruitment of juvenile brown trout at Malin Bridge in 2010 and the progression to age 1 subadult cohort in 2011, plus greater abundance of adult brown trout at Malin Bridge post-RRW than the control site. 

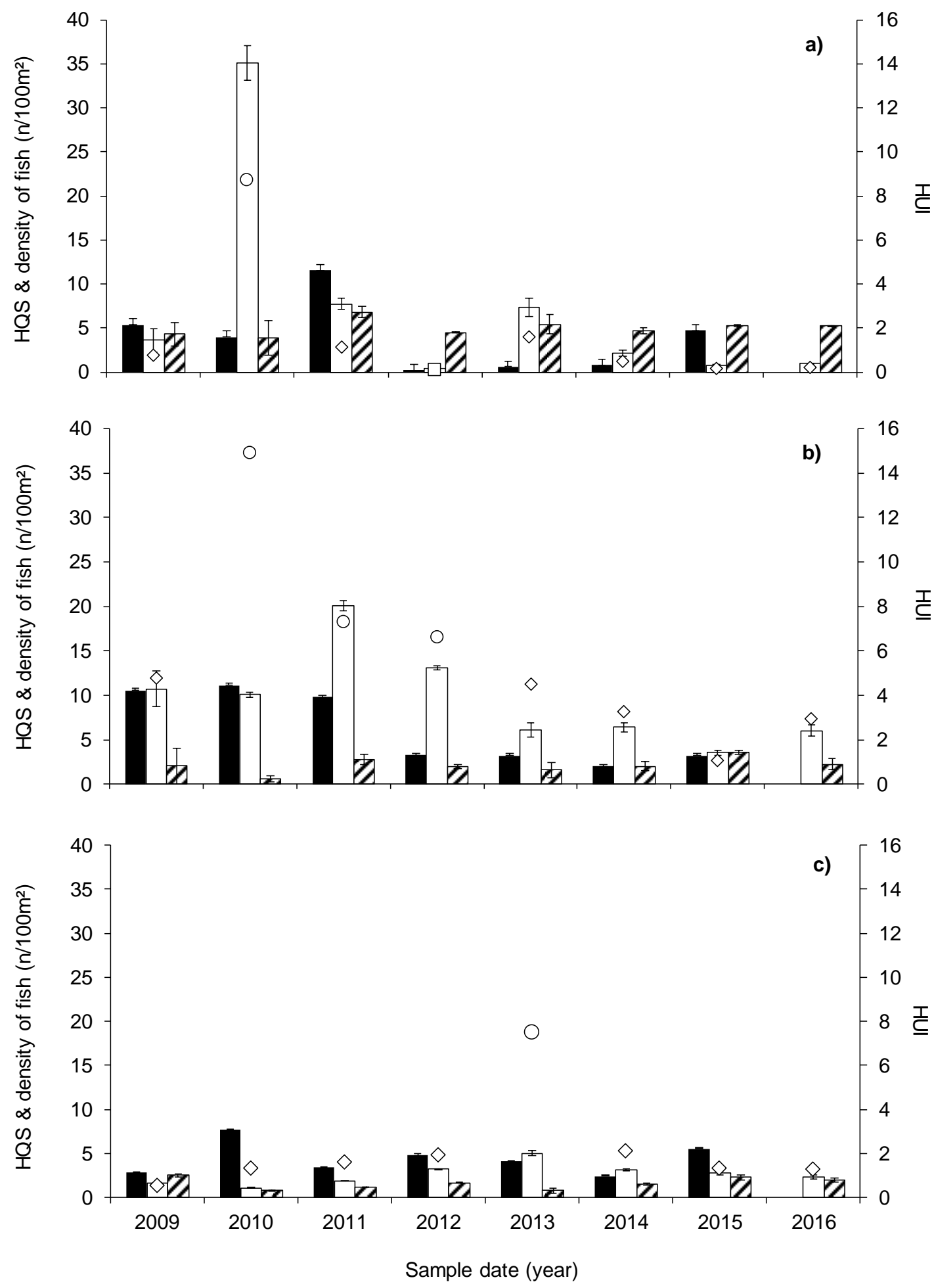

Figure 6. Density estimates (95\% confidence limits) for the control site (black bars) Malin Bridge (white bars), Habitat Quality Score (HQS; 90\% confidence limits, hatched bars), and Habitat Utilisation Index ( $\mathrm{HUI}$; white points) for a) juvenile $0+$, b) sub-adult $\geq 1+(<20 \mathrm{~cm})$ and $\mathrm{c}$ ) adult $\geq 1+(>20 \mathrm{~cm})$ brown trout at Malin Bridge on the River Loxley, northern England, pre-flood risk management (2009), post-flood risk management (2010) and post-river restoration (2011-2016). Diamonds denote HUls not significantly higher or lower than expected, circles denote HUls significantly higher than expected, 
squares denote HUls significantly lower than expected. Note no data were available for the control in 2016.

\section{Discussion}

RRW at the study site created a more heterogeneous channel than post-FRM. The characteristics were, similar to pre-FRM through increased diversity of physical habitat and flow complexity by the addition of large boulders, cobbles and gravel, which provide cover for fish. Post-RRW (2011-2016) the diversity of flow types increased compared to the previous two years, but turbulent shallow water remained the dominant flow type, while cobbles remained the dominant substrate type, and sources of cover for trout $\leq 20 \mathrm{~cm}$ remained low across all years (2011 to 2016). Furthermore, cobbles $(6.4-25.6 \mathrm{~cm}$ ) and gravel $(0.2-6.4 \mathrm{~cm})$ were always the dominant substrate categories throughout the whole study period (20092016), and both categories provide suitable cover and spawning habitat for juvenile (5-8 cm in length) and sub-adult trout $(9-20 \mathrm{~cm})$, for juvenile $(4-5 \mathrm{~cm}$ in length) and adult $(6-9 \mathrm{~cm}$ in length) bullhead (Maitland 2004).

The changes in hydrogeomorphology post-FRM were as designed, whilst post-RRW habitat changed progressively and seemed to revert to the original channel characteristics, including growth of riparian vegetation. This is likely because the rivers Rivelin and Loxley are highly dynamic with frequent spate flows that mobilise the gravels and cobbles at the site but more importantly deposit gravels from upstream at the Malin Bridge study site as a result of the hydraulics created by the road bridge at the bottom of the site.

Fish species composition, and more specifically brown trout densities, for all age categories were not negatively affect by the FRM. Densities of adult brown trout fish were comparable between pre and post-FRM, while densities of juvenile bullhead and brown trout increased dramatically. FRM created a homogeneous channel by extensive tree management (removal), modifications to the riverbed and overall changes to flow and depth. FRM engineering was expected to result in habitat degradation for fish (Tomlinson and Perrow 2003), yet the densities of juvenile brown trout and bullhead were significantly higher post-FRM. The shallow riffles and clean coarse gravel created by the FRM works possibly provided good spawning and nursery habitats (Maitland 2004), prior to brown trout and bullhead spawning in late 2009 and early 2010, respectively, thus contributing to the increase in juvenile density. Although the river at the study site was significantly shallower after FRM in 2010, depth does not become a critical factor for juvenile brown trout or bullhead survival until it is $<5 \mathrm{~cm}$ and too shallow to provide suitable refuge habitat or result in stranding (Utzinger et al. 1998). Additionally, the high density of juvenile brown trout in 2010 could also have been partly attributed to an unrelated increase in spawning success and survival (e.g. linked to catchment-wide or regional environmental conditions), but this was not evident at the control site upstream of Malin Bridge, where juvenile densities was lower.

The abundances of sub-adult and adult brown trout were marginally lower post-FRM and this was expected because key habitat features that provide sources of cover for $\leq 20 \mathrm{~cm}$ trout were extremely low. For example, large stones, woody debris and tree roots that provide cover for sub-adult and adult 
fish was removed during the FRW (Punchard et al 2000; Forseth \& Harby 2014). The number of adult bullhead increased post-FRM, which was unexpected, but perhaps a similar response to juvenile brown trout where the shallow gravel habitat created post-FRM was suitable to sustain the population.

There was a shift in trajectory of species composition between pre-FRM and post-RRW and across all post-RRW years (2011 to 2016), but at no point did species composition return to that prior to FRM, although this was not necessarily expected as the channel morphology post-RRW did not return to preFRM form in its entirety. However, the channel did start to reset over the 5 years post RRW, but riparian vegetation and gravel shoal bars were not as extensive as prior to the FRM. Cowx et al. (1986) found that recovery of fish communities in regraded rivers took 5-10 years to recover to former composition and it is likely the site at Malin Bridge is still evolving along this trajectory. In the short-term (2010-2011), the shift in species composition post-RRW (2009) was due to increased numbers of juvenile and adult bullhead and adult brown trout and steady decline of juvenile brown trout abundance which further decrease in 2012, before slightly increasing and remaining at a similar level across 2013 to 2016 . Furthermore, the overall densities for juvenile and sub-adult brown trout were lower when compared to 2009, this trend was also found in control site and it is therefore possible that the FRM and RRW were not directly responsible for this decrease and natural variability should be considered a factor. Furthermore, in 2012, the decrease in juvenile brown trout and bullhead could be a result of washout due to exceptional high flows in spring-summer 2012 (April, June and July, Appendix 1).

There was a further change in the trajectory of species composition in 2013 due to a net increase in juvenile brown trout and bullhead abundance followed by a small decrease in juvenile brown trout and adult bullhead abundance between 2013 and 2014. A net decrease in adult bullhead caused a further change in trajectory for 2015 and 2016. Local physical habitat conditions, namely flow (hydrology) and substratum composition (morphology), are important characteristics for brown trout and bullhead, and there is a clear causative link between biological communities and complex habitats at local scales (Tomlinson and Perrow 2003; Stoll et al. 2016). Nevertheless, despite the RRW the species composition did not return to pre-FRM (2009) within the time scale of the study, this may take more time as the channel stabilises over the next few years.

Post-FRM (2009), the HQS for juvenile, sub-adult and adult brown trout reduced to the lowest in the study period and while the observed density was only slightly lower than pre-FRM for all age classes, they were significantly higher than expected. These findings were unexpected as brown trout is territorial and evidence indicates that poor habitat quality can lead to subordinate brown trout leaving the site (Höjesjö et al. 2007; Jonsson \& Jonsson 2011). However, because adult trout densities did not reduce post-FRM, it is possible they could have moved out of the immediate area of the FRM works and rapidly recolonised once the works were complete to utilise available habitat.

HQS densities for juvenile, sub-adult and adult brown trout increased post-RRW (2011) and were comparable with observed densities, with the exception of sub-adult trout where the observed densities 
were significantly higher than the HQS. The larger observed densities of sub-adult trout in 2011 was likely a result of good recruitment of juvenile trout in 2010. Long-term (2011-2016) the HQS densities of juvenile, sub-adult and adult brown trout post-RRW varied little, and were comparable to pre-FRM but higher than post-FRM. These measures of habitat quality suggest that the FRM degraded the habitat for trout in the main, but RRW subsequently improved habitat complexity, which is what would be expected given the objectives of the works (Whiteway et al. 2010; Williams et al. 2015). However, the observed brown trout density were typically higher than the HQS possibly because the study site is located in an urban, heavily engineered reach of river where the overall habitat lacks complexity. Both brown trout and bullhead are highly plastic in their life histories and have evolved to live in highly dynamic and unpredictable upland rivers. They are thus resilient to changes in flow events and suboptimal habitat (Jonsson \& Jonsson 2011). Notwithstanding, if FRM is performed in rivers populated by different fish species, reductions in fish densities may occur, especially after elevated flow events.

Overall, the performed FRM works did not evidently decrease habitat quality nor fish density based on the data available. This was not expected given there is a wealth of evidence to show that engineering rivers degrades habitat, and was therefore an expected outcome of the FRM works at Malin Bridge. Furthermore, the results in this study demonstrate that integrating river restoration works into the planning and implementation of flood risk management can mitigate some potentially detrimental effects of flood risk management actions, and can protect ecosystem functioning and restore essential habitat for aquatic biota. We recommend further investigations into the ecological impacts of FRM and RRW works using other cases study sites.

It is essential that flood risk management does not just focus on reducing exposure and vulnerability of people and infrastructure to floods (Hansen et al. 2011) but also to consider the ecological impacts, which are known to be negative. Therefore it is critical that river restoration works are incorporated into flood risk management planning and implementation, as recommended by Angelopoulos et al. (2017), to support the overarching policy objectives of two conflicting, cross sectoral measures. This will ensure a balance between societal needs to reduce the impacts of flooding impact while protecting the aquatic environment. 
References

Acreman, M.C., Ferguson, A.J.D., 2010. Environmental flows and the European Water Framework Directive. Freshwater Biol. 55, 32-48.

Acreman, M.C., I.C. Overton, J. King, P.J. Wood, I.G. Cowx, M.J. Dunbar, E. Kendy., W.J. Young. 2014. The changing role of ecohydrological science in guiding environmental flows, Hydrological Sciences Journal. 59(3-4), $433-450$.

Adams, V.M., Ivarez-Romero, J.G.A., Carwardine, J., Cattarino, L., Hermoso, V., Kennard, M.J., Linke, S., Pressey, R.L., Stoeckl, N., 2014. Planning across freshwater and terrestrial realms: cobenefits and trade-offs between conservation actions. Conserv. Lett. 7, 425-440.

Angelopoulos, N.V., Cowx I.G., Buijse, A.D., 2017. Integrated planning framework for successful river restoration projects: upscaling lessons learnt from European case studies. Environ. Sci. Policy. 76, 12-22.

Bagenal, T.B., Tesch, F.W., 1978. Age and growth, in: Bagenal, T.B. (Eds.), Methods for Assessment of Fish Production in Fresh Waters, third ed. Blackwell Scientific Publications., pp. 101-136.

Barnard, S., Wyatt, R.J., 1995. A guide to HABSCORE field survey methods and the completion of standard forms. Report to NRA, No. 401, WRc.

Bernhardt, E.S., Palmer, M.A., 2007. Restoring streams in an urbanizing world. Freshwater Biol. 52, 738-751.

Bray, J.R., Curtis, J.T., 1957. An ordination of the upland forest communities of Southern Wisconsin. Ecol Monograph. 27, 325-349.

Butler, C., Pidgeon, N., 2011. From 'flood defence' to 'flood risk management': exploring governance, responsibility, and blame. Environ. Plan. C Gov. Policy. 29, 533-547.

Carle, F.L., Strub, M.R., 1978. A new method for estimating population size from removal data. Biometrics. 34, 621-630.

Collas, F.P.L., Buijse, A.D., Van den Heuvel, L., Van Kessel, N., Schoor, M.M., Eerden, H., Leuven, R.S.E.W. 2018. Longitudinal training dams mitigate effects of shipping on environmental conditions and fish density in the littoral zones of the river Rhine. Sci. Total Environ. 619-620, 1183-1193. doi: 10.1016/j.scitotenv.2017.10.299.

Cowx, I. G., Wheatley, G.A., Mosley, A., 1986. Long-term effects of land-drainage works on fish stocks in the upper reaches of a lowland river. Environ. Manage. 22, 147-156.

Everard, M., Moggridge, H.L., 2012. Rediscovering the value of urban rivers. Urban Ecosyst. 15, 293314.

Friberg, N., Angelopoulos, N.V., Buijse, A.D., Cowx, I.G., Kail, J., Moe, T.F., Moir, H., O'Hare, M.T., Verdonschot, P.F.M., Wolter, C., 2016. Effective river restoration in the 21st century: from trial and error to novel evidence-based approaches. Adv. Ecol. Res. 55, 535-611.

Forseth, T., Harby, A., eds., 2014. Handbook for environmental design in regulated salmon rivers. Trondheim: NINA Special Report 53.

Hansen, J. P., Wikström, S. S., Axemar, H., Kautsky, L., 2011. Distribution differences and active habitat choices of invertebrates between macrophytes of different morphological complexity. Aquat. Ecol. 45, 11-22.

Heino, J., 2013. The importance of metacommunity ecology for environmental assessment research in the freshwater realm. Biol. Rev. 88, 166-178.

Höjesjö, J., Okland, F., Sundstrom, L. F., Pettersson J., Johnsson, J. I., 2007. Movement and home range in relation to dominance; a telemetry study on brown trout Salmo trutta. J. Fish. Biol. 70, 257-268.

IPCC., 2014. Climate Change 2014: Synthesis Report. Contribution of Working Groups I, II and III to the Fifth Assessment Report of the Intergovernmental Panel on Climate Change [Core Writing Team, R.K. Pachauri and L.A. Meyer (eds.)]. IPCC, Geneva, Switzerland, pp 151.

Jackson, M.C., Weyl, O.L.F., Altermatt, F., Durance, I., Friberg, N., Dumbrell, A.J., Piggott, J.J., Tiegs, S.D., Tockner, K., Krug, C.B., Leadley, P.W., Woodward, G., 2016. Recommendations for the next generation of global freshwater biological monitoring tools. Adv. Ecol. Res. 55, 615-636.

Jonkman, S.N. Vrijling, J.K., Vrouwenvelder, A.C.W.M., 2008. Methods for the estimation of loss of life due to floods: a literature review and a proposal for a new methods. Nat. Hazards. 46, 353389.

Jonsson, B., Jonsson, N., 2011. Ecology of Atlantic Salmon and Brown Trout. Habitat as a template for life histories. Fish \& Fisheries Series 33. Springer, Dordrecht, the Netherlands.

Junk WJ, Bayley PB, Sparks RE. 1989. The flood pulse concept in river-floodplain systems. Canadian Special Publication of Fisheries and Aquatic Sciences. 106, 110-127. 
Mainstone, C.P., Holmes, N.T.H., 2010. Embedding a strategic approach to river restoration in operational management processes - experiences in England. Aquatic Conserv: Mar. Freshw. Ecosyst. 20, 582-595.

Maitland, P.S., 2004. Keys to the Freshwater Fishes of the British Isles and Ireland, with notes on their distribution and ecology. Freshwater Biological Association. Scientific Publication No. 62.

Milner, N. J., Wyatt, R.J., Broad, K., 1998. HABSCORE - applications and future developments of related habitat models. Aquatic Conserv: Mar. Freshw. Ecosyst .8, $633-644$.

Pitt Review., 2008. "Learning lessons from the 2007 floods", http://archive.cabinetoffice.gov.uk/pittreview/ /media/assets/www.cabinetoffice.gov.uk/flooding review/pitt review full\%20pdf.pdf.

Punchard, N.T., Perrow, M.R., Jowitt, A.J.D., 2000. Fish habitat associations, community structure, density and biomass in natural and channelized lowland streams in the catchment of the River Wensum, UK, in: Cowx, I.G. (Eds), Management and Ecology of River Fisheries. Blackwell Science, Oxford, pp. 143-157.

Radinger, J., Wolter, C., 2015. Disentangling the effects of habitat suitability, dispersal and fragmentation on river fish distribution. Ecol. Appl. 25, 914-927.

Roni, P., Beechie, T., 2013. Stream and watershed restoration - A guide to restoring riverine processes and habitats. John Wiley \& Sons, Ltd.

Rouillard, J. J., Ball, T., Heal, K. V., Reeves, A.D. 2015. Policy implementation of catchment-scale flood risk management: Learning from Scotland and England. Environ. Sci. Policy. 50, 155-165.

Sayers, P., Sayers, Y., L.i, G., Galloway, E., Penning-Rowsell, F., Shen, K., Wen, Y., Chen., T. Le Quesne., 2013. Flood Risk Management: A Strategic Approach. Paris, UNESCO.

Stoll, S., Breyer, P., Tonkin, J.D., Früh, D., Haase, P., 2016. Scale-dependent effects of river habitat quality on benthic invertebrate communities - Implications for stream restoration practice. Sci. Total Environ. 553, 495-503.

Tockner K, Malard F, Ward JV. 2000. An extension of the Flood Pulse Concept. Hydrological Processes. 14, 2861-2883.

Tomlinson, M.L., Perrow, M.R., 2003. Ecology of the Bullhead. Conserving Natura 2000 Rivers Ecology Series No. 4. English Nature, Peterborough.

Utzinger, J., Roth, C.. Peter, A., 1998. Effects of environmental parameters on the distribution of bullhead Cottus gobio with particular consideration of the effects of obstructions. J. Appl. Ecol. 35, 882-892.

Weber, A., Wolter, C., 2016. Habitat rehabilitation for juvenile fish in urban waterways: A case study from Berlin, Germany. J. Appl. Ichthyol. 33, 136-143.

Whiteway, S.L., Biron, P.M., Zimmermann, A., Venter, O., Grant, J.W.A., 2010. Do instream restoration structures enhance salmonid abundance? A meta-analysis. Can. J. Fish. Aquat. Sci. 67, 831841.

Wiering, M., Liefferink, D., Crabbe, A., 2017. Stability and change in flood risk governance: on path dependencies and change agents. Journal of Flood Risk Management. DOI: $10.1111 /$ jfr3.12295.

Williams, J. E., Isaak, D. J., Imhof, J., Hendrickson, D. A., McMillan, J. R., 2015. Cold-water fishes and climate change in North America. Reference Module in Earth Systems and Environmental Sciences.

Wyatt, R.J., Barnard, S., Lacey R. F., 1995. Use of HABSCORE V software and application to impact assessment. Report to NRA No. 400, WRc.

Zajicek, P., Radinger, J., Wolter, C. 2018. Disentangling multiple pressures on fish assemblages in large rivers. Sci. Total Environ. 627,1093-1105. doi:10.1016/j.scitotenv.2018.01.307. 


\section{Supplementary material}

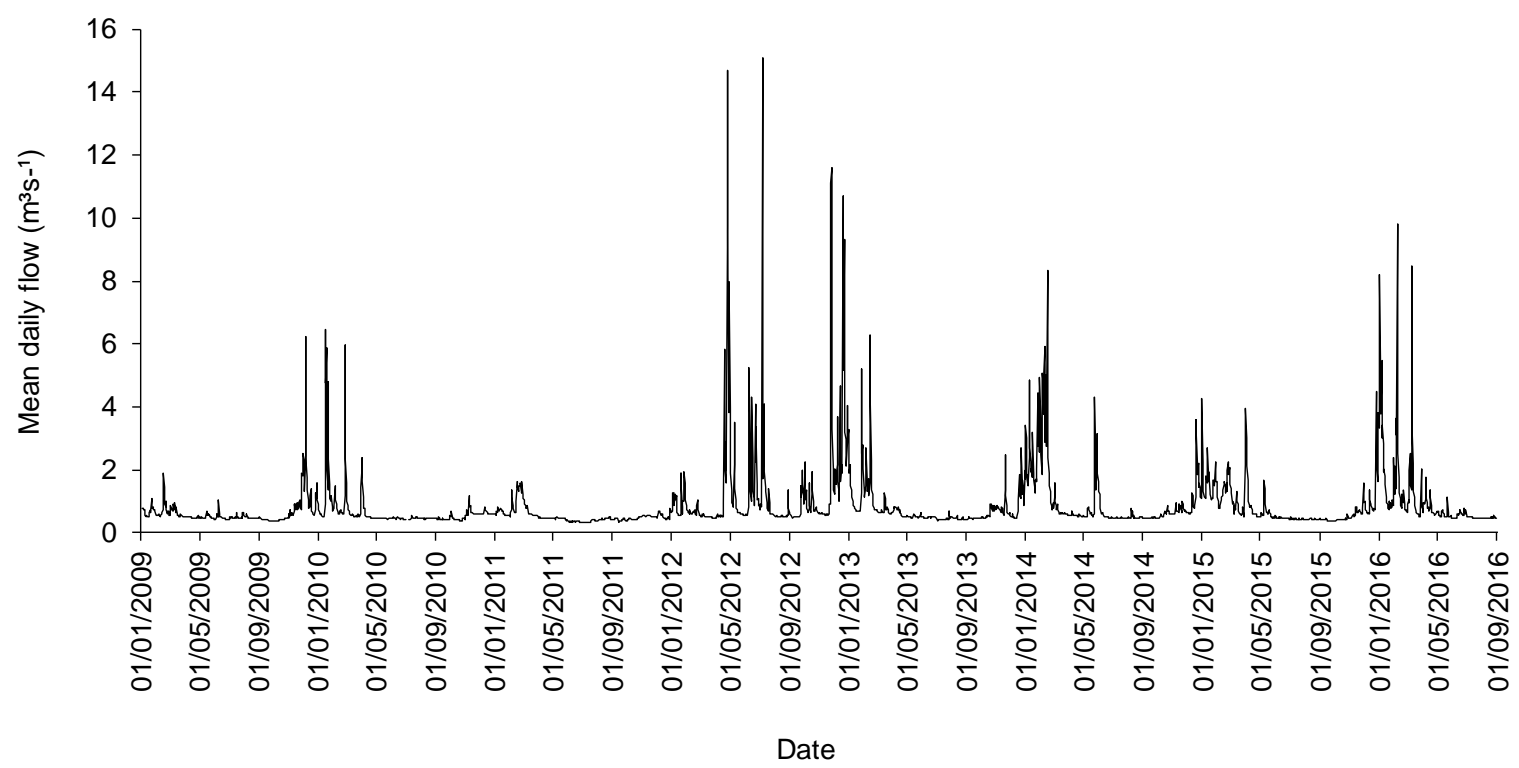

Appendix 1. Mean daily flow ( $\mathrm{m}^{3} \mathrm{~s}^{-1}$; Loxley Rowel Bridge Gauge $\left.53.401963-1.551268\right)$.

Appendix 2. Number of fish species caught each sampling year.

\begin{tabular}{ccccccccccc}
\hline $\begin{array}{c}\text { Sampling } \\
\text { year }\end{array}$ & $\begin{array}{c}\text { Brown } \\
\text { trout }\end{array}$ & Bullhead & $\begin{array}{c}\text { Stone } \\
\text { loach }\end{array}$ & Perch & Pike & Minnow & Roach & $\begin{array}{c}\text { Mirror } \\
\text { carp }\end{array}$ & $\begin{array}{l}\text { 3 Spined } \\
\text { stickleback }\end{array}$ & $\begin{array}{l}\text { Lamprey } \\
\text { ammocoete }\end{array}$ \\
\hline 2009 & 107 & 148 & 5 & 3 & 0 & 0 & 1 & 0 & 0 & 0 \\
2010 & 359 & 314 & 5 & 6 & 0 & 0 & 0 & 1 & 0 & 0 \\
2011 & 203 & 226 & 2 & 0 & 0 & 0 & 0 & 0 & 0 & 0 \\
2012 & 130 & 146 & 4 & 24 & 1 & 0 & 0 & 0 & 2 & 0 \\
2013 & 129 & 208 & 3 & 15 & 1 & 1 & 0 & 0 & 0 & 0 \\
2014 & 74 & 199 & 3 & 6 & 1 & 0 & 0 & 0 & 0 & 0 \\
2015 & 61 & 87 & 1 & 8 & 1 & 0 & 0 & 0 & 0 & 1 \\
2016 & 66 & 91 & 2 & 0 & 4 & 5 & 0 & 0 & 0 & 0 \\
\hline
\end{tabular}

